\title{
Testing time for Russian lessons
}

\section{Mathematicians say Russia's education reforms are a formula for disaster.}

\section{Obrazovaniye, Kotoroye My Mozhem Poteryat (The Education That We May Lose) \\ editor-in-chief V. A. Sadovnichii \\ Moscow State University Press/Institute for Computer Research: 2002. 288 pp. 300 roubles}

\section{Valery N. Soyfer}

The Russian Ministry of Education plans to lengthen high-school education from 11 to 12 years and to replace university entrance exams with a unified examination system. The students' grades in these final highschool examinations will determine the level of funding that their universities will subsequently receive from the state. In September last year, the balance of subjects taught in high schools changed, with less time spent on mathematics and natural sciences, and more on the social sciences, information technology, local geography and ecology, physical education and, more worryingly, patriotic education and military training.

Most education specialists are opposed to these changes. A group of leading mathematicians, headed by Victor A. Sadovnichii, president of Lomonosov Moscow State University, has openly taken a stance against the reforms by publishing this book.

In a recent speech, the text of which opens this book, Russian President Vladimir Putin stated in general terms the importance of education and the need for reform. In their introductory article, Sadovnichii and Zhores Alferov, who won the 2000 Nobel Prize in Physics, consider in detail how such reform can be brought to education. They object to "attempts to impose quasi-market mechanisms" on the education system, and to the commercialization of high-school and university education.

Vladimir Arnold calls the proposed reforms a "preparation for a new Cultural Revolution" reminiscent of the crushing of Chinese culture and education by the communist government of Mao Tse-tung. He is concerned that the damage to Russia's higher education and culture would be long term and difficult to correct.

Of course, these reforms are not the first to have been attempted in the past hundred years. During the 75 years of communist rule there were several attempts to change the high level of education that existed in Russia under the tsars, but nevertheless, until recently, the traditions of one of the best secondary-education systems in the world were maintained. Sadovnichii, in a central article, points out that education traditionally "distinguished Russia in Tsarist times,

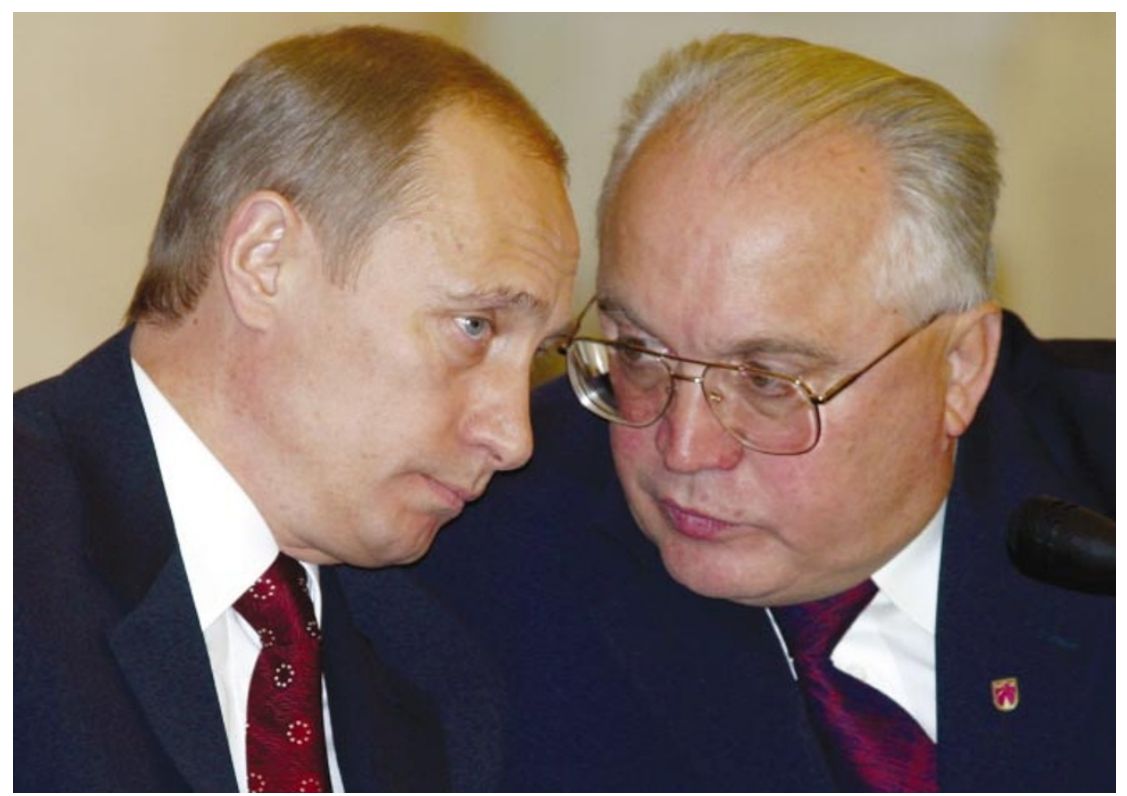

A word in your ear: Victor Sadovnichii (right) urges President Vladimir Putin to rethink on education.

the Soviet period, and today... The virtues of the Russian higher school, which the entire world spoke about with real respect, have always depended first of all on fundamental science, and on the scientific schools."

Examining the history of educational reforms in Russia in detail, Lev D. Kudryavtsev concludes that the innovations proposed particularly the reduction in the level of teaching in mathematics and the natural sciences - may have disastrous effects on the country's future. He also expresses concern about the linking of university funding to the grades obtained by students in uniform state exams, given "the level of corruption that exists in our modern society".

The book is given emotional impetus by the transcript of a television interview given by Nobel laureate Aleksandr Solzhenitsyn, who worked for many years as a high-school teacher. He was concerned that the lack of state funding has led to the delapidation of many schools, particularly in rural areas. This, coupled with the high mortality rate in these areas, may mean that by 2010 "the number of school-aged children will have decreased by 30 percent... This means that the smaller rural schools will close. In the expanses of Russia the hearths of education will cease to glow."

Another former high-school teacher, Igor F. Sharygin, argues that mathematics should become a cornerstone of Russian education. He says that people who are mathematically literate and who understand what proof means cannot easily be manipulated: "Math- ematics and state authority are two incompatible things, but rational sovereigns often run to mathematicians to resolve the most varied problems in difficult moments."

To substantiate their arguments, the editors have included a full translation of a report from the US National Commission on Mathematics and Science Teaching (the John Glenn Commission), along with the text of a programme of educational reforms proposed by US President George W. Bush. According to these documents, which take up nearly 100 pages, the US leadership is determined to counter the decline in the standard of mathematics and science teaching in US secondary schools. The editors of this book point out that while the United States is trying to improve its standard of teaching, the Russian government is taking measures in the opposite direction.

The publication of this book strikes me as an unusual step. Sadovnichii, the book's editor-in-chief, is one of Russia's best academic administrators, and the fact that he has taken to open and dispassionate conflict with the ministry of education is symbolic of a genuine civil society developing in Russia. It also provides evidence that the interests of society are being taken up by the most important leaders, rather than being concealed within the offices of the bosses, as happened in the Soviet period. Sadovnichii and his co-authors are to be applauded for their civil and open position.

Valery N. Soyfer is at George Mason University, Fairfax, Virginia 22030, USA. 